\title{
New Photobiomodulation Device for Prevention and Cure of Radiotherapy-induced Oral Mucositis and Dermatitis: Results of the Prospective Safe PBM Study
}

Rene-Jean Bensadoun ( $\sim$ rjbensad@gmail.com )

Centre de Haute Energie (CHE) https://orcid.org/0000-0003-1290-7497

Marc A Bollet

Clinique Hartmann

Xavier Liem

Centre Oscar Lambret

Kim Cao

Institut Curie

Nicolas Magné

Institut de Cancérologie de la Loire: Institut de Cancerologie de la Loire

\section{Research Article}

Keywords: Photobiomodulation, Breast cancer, Head and neck cancer, Oral mucositis, Radiation dermatitis

Posted Date: July 23rd, 2021

DOI: https://doi.org/10.21203/rs.3.rs-611879/v1

License: (c) (1) This work is licensed under a Creative Commons Attribution 4.0 International License.

Read Full License

Version of Record: A version of this preprint was published at Supportive Care in Cancer on September 19th, 2021. See the published version at https://doi.org/10.1007/s00520-021-06574-2. 


\section{Abstract}

\section{Purpose}

To assess the feasibility, safety and tolerability of CareMin650, a new photobiomodulation device, in patients treated by radiotherapy (RT). To collect preliminary data on efficacy for prevention and treatment of oral mucositis (OM) and radiation dermatitis (RD).

\section{Methods}

French, multicentric, prospective, non-comparative study. Inclusion of patients with head and neck cancer $(\mathrm{H} \& \mathrm{NC}$, cohort $\mathrm{A})$ or breast cancer $(\mathrm{BC}$, cohort $\mathrm{B})$ treated in prophylactic (cohorts $\mathrm{A} 1$ and $\mathrm{B} 1)$ or curative setting (cohort A2 and B2). Prophylactic treatment was administered from D1 to end of RT, at a dose of 3 $\mathrm{J} / \mathrm{cm}^{2}$. Curative treatment started when a grade 1 to grade 3 lesion had occurred and was pursued until end of RT. Primary endpoint was incidence of device-related adverse events (AEs). OM and RD lesions were graded according to CTCAE V3.

\section{$\underline{\text { Results }}$}

Overall, 72 patients were included $(22,9,23$ and 18 in cohorts A1, A2, B1 and B2 respectively). No devicerelated AE was reported after 1,312 CareMin 650 sessions. In cohorts $A 1$ and $B 1$, median time to first $\mathrm{OM}$ or $\mathrm{RD}$ lesion was 20 days. One BC patient developed G3 RD after completion of RT and discontinuation of CareMin650. Four H\&NC patients developed G3 OM. In cohorts A2 and B2, lesions improved or stabilized in $71 \%$ of patients. Rates of satisfaction were high among patients and users.

\section{Conclusion}

CareMin650 is feasible, safe and well tolerated for preventive or curative treatment of OM and RD in cancer patients treated with RT. Preliminary efficacy results are promising.

\section{Introduction}

Oral mucositis (OM) and radiation dermatitis $(\mathrm{RD})$ are among the most frequent and disabling side-effects of radiotherapy (RT). OM affects nearly all patients treated with RT \pm chemotherapy (CT) for head and neck cancer $(\mathrm{H} \& N C)^{1}$, resulting in dysphagia and pain, weight loss and necessity of enteral alimentation in some cases, as well as increased risk of infections with potentially life-threatening sepsis ${ }^{2-5}$. OM may jeopardize planned anticancer treatment, potentially leading to decreased efficacy ${ }^{3}$. OM-related consequences significantly increase the cost of patients' management ${ }^{4}$ and impair quality of life (QoL). Very few options showed efficacy for prophylaxis and/or treatment of $\mathrm{OM}$, despite a huge variety of treatments experimented. However, low-level laser therapy (LLLT), now referred to as photobiomodulation (PBM), demonstrated significant benefits in several randomized clinical trials, in particular in patients with $\mathrm{H} \& \mathrm{NC}^{6-11}$. According to recent guidelines, $\mathrm{PBM}$ is recommended to prevent $\mathrm{OM}$ in patients receiving high 
dose CT as a conditioning regimen for stem cells transplantation (SCT) and in patients undergoing RT for $\mathrm{H} \& \mathrm{NC}^{12,13}$.

$\mathrm{RD}$ affects approximately $95 \%$ of patients who receive $\mathrm{RT}^{14}$, ranging from mild erythema to dry or moist desquamation and ulceration ${ }^{15}$. Nearly all women treated with RT for breast cancer (BC) experience some degree of $\mathrm{RD}^{16}$. High-quality data are still insufficient to support specific strategies in the management of $\mathrm{RD}^{15}$. However, there is increasing evidence on the benefits of PBM in this setting ${ }^{17}$.

PBM involves absorption of red and near infrared light by mitochondrial chromophores. The electron transfer rate of the respiratory chain is increased, driving upward the production of adenosine triphosphate, reactive oxygen species and nitric oxide, thus simulating genes involved in tissue repair. Factors involved in inflammation and immunity are recruited to act at a tissue level ${ }^{18-20}$. Thus, PBM impacts all the stages of wound repair and tissue regeneration. It also prevents fibrosis, reduces pain (absorption of energy by nociceptors) and prevents tissue death ${ }^{19,21}$.

CareMin650 has been developed to improve practical use of PBM. Delivery of light, emitted by a flexible surface (fabric made of woven optic fibres) in contact with the skin or mucosa, is accurately controlled, reproducible and operator independent. The device consists of an electronic box generating the light, and pads connected to the box through an optic fibre cable: either oral pads measuring $2,6 \star 5,5 \mathrm{~cm}^{2} \mathrm{emitting}$ light on both sides or derma pads measuring $15,6 \star 5,5 \mathrm{~cm}^{2}$, emitting light on one side (Fig. 1). The dose in $\mathrm{J} / \mathrm{cm}^{2}$ is selected on the light box that calculates automatically the length of the session to reach the selected dose. Disposable single use sleeves are placed on the pads before applying them to the skin or the mucosa. The main objectives of this study were to show feasibility, safety and tolerability of CareMin650 and provide preliminary data on efficacy.

\section{Methods}

\section{- Design and Patients}

Safe PBM was a French multicentric prospective non comparative study, designed to assess CareMin650 in patients with $\mathrm{H} \& N C$ (cohort A) or BC (cohort B), in prophylaxis (cohorts A1 and B1) or cure (cohorts A2 and B2) (Supplementary Fig. 1). Eligible patients were aged 18 years or above, had histologically proven cancer (BC in cohorts B1 and B2, squamous cell carcinoma of oropharynx, nasopharynx, hypopharynx, larynx or oral cavity in cohorts A1 or A2), and ECOG performance status $\leq 2$. In preventive cohorts, patients were scheduled to receive RT (on at least $50 \%$ of the oral mucosa, at a total dose of at least 40 Gy for $\mathrm{H} \& \mathrm{NC}$ ) and had no lesions at inclusion. In cohorts A2 and B2, patients had previously started RT and presented with $\mathrm{OM}$ and/or RD lesions of grade 1 to 3 . $\mathrm{BC}$ patients were required to have undergone tumor resection (breast conservative surgery or mastectomy) while prior surgery was not mandatory in cohorts A1 or A2. In all cohorts, concomitant treatment with CT and / or targeted therapies was permitted. Patients were excluded if they had known allergy to polyurethane. In H\&NC patients, specific exclusion criteria were active bleeding or high risk of bleeding, $\mathrm{Hb}<8 \mathrm{~g} / \mathrm{dL}$, neutrophils $<1000 \mathrm{~mm}^{3}$, or platelets $<50000 / \mathrm{mm}^{3}$. In 
cohorts B1 and B2, patients were excluded if they had received prior irradiation to the same breast. Consecutive patients were included in each subgroup, until the target number had been reached. All study procedures were in accordance with the ethical standards and with the 1964 Helsinki Declaration. All patients signed informed consent before any study procedure was implemented. The study was approved by the Comité de Protection des Personnes (CPP) CPP Sud-Est VI and by the ANSM (Agence Nationale du Médicament et des Produits de Santé).

\section{- Treatment}

CareMin650 started at inclusion in the study and was pursued until the end of RT. The minimal number of sessions per week was 3, performed immediately before or after RT; however 5 sessions/week were recommended. Any healthcare professional could administer the treatment after appropriate training. Oral pads and derma pads delivered red light with wavelength of $650 \mathrm{~nm}$, and irradiance between 10 and 50 $\mathrm{mW} / \mathrm{cm}^{2}$. Doses for prophylactic and curative treatments were $3 \mathrm{~J} / \mathrm{cm}^{2}$ and $6 \mathrm{~J} / \mathrm{cm}^{2}$ respectively. If OM or $\mathrm{RD}$ occurred in a patient from a prophylactic cohort, the dose was increased to $6 \mathrm{~J} / \mathrm{cm}^{2}$. Conversely, if lesions in patients from curative cohorts resolved before the end of RT, the dose was decreased to 3 $\mathrm{J} / \mathrm{cm}^{2}$. In cohorts A1 and B1, pads were applied on irradiated areas presenting a risk of RT-related complications. In cohorts A2 and B2, pads were applied on each lesion.

Standard $\mathrm{OM}$ and RD prophylaxis, including oral hygiene using soft toothbrush and bicarbonate mouthwashes for OM, was implemented according to sites' habits. In case of lesions, usual local care, analgesics and corticosteroids were allowed and therapies considered necessary for the subject's wellbeing could be administered at the discretion of the investigator. Keratinocyte growth factors (palifermin) and other PBM treatments were not allowed during the study.

\section{- Assessments}

Safety was assessed throughout the study, adverse events (AEs) were graded according to NCI CTCAE v4. Examination of skin and oral mucosa was performed at each CareMin650 session to assess local tolerance and detect any new lesion. In case of lesion, time of occurrence, size, location, grade according to $\mathrm{NCI} C \mathrm{CTCAE} \mathrm{v} 3$ and time to resolution (defined as lesion not requiring further treatment) were reported. Once a week, data were collected on pain, using a Visual Analogic Scale (VAS) graded from 0 (no pain) to 100 (intolerable pain), analgesic consumption, xerostomia and in case of OM, consequences on food intake. Quality of life was assessed using the SF-12 questionnaire, filled in at baseline and at the end of RT. Patients' and users' satisfaction questionnaires were filled in at the end of RT. A follow-up visit was performed $10 \pm$ days after the end of treatment visit.

\section{- Statistics}

The safety and modified intention-to-treat (mITT) sets comprised all included subjects who had at least one CareMin650 session and at least one safety or efficacy evaluation respectively. The per protocol (PP) set comprised all subjects without major protocol violation, defined by i) less than 10 CareMin650 sessions in cohorts A1 or B1 or less than 5 sessions in cohorts A2 or B2, or ii) start of CareMin 650 more 
than 3 days after start of RT in cohorts A1 or B1. The primary endpoint of the study was the rate of devicerelated AEs. Secondary endpoints included incidence and grade of lesions, pain, patients' and users' satisfaction.

The number of observations needed was estimated at 300 to allow detecting an undesirable effect occurring at a frequency of $1 \%$ with a probability of $95 \%{ }^{22}$. Assuming that patients would undergo at least 10 sessions on average, the total number of patients to analyze was set at 60 . With an estimation of $20 \%$ not eligible for analysis, the total number of subjects to include was 72 . Analyses were only descriptive. Quantitative variables were described by mean, standard deviation, median, minimum and maximum. Qualitative variables were described by counts and percentages. No statistical test was performed. Missing date were not replaced.

The study is registered with ClinicalTrials.gov, number NCT03988556

\section{Results}

Patients were recruited from July 2019 to November 2020. In total, 74 were screened, 72 were included and analysed in the mITT set $(22,9,23$ and 18 patients in cohorts A1, A2, B1 and B2 respectively), while 58 were analysed in the PP population (17, 8, 19 and 14 patients respectively) (Fig. 2). Baseline characteristics are summarized in Table 1. Median age was 61.4 years. Relevant comorbidities were more frequent in cohorts $A$ than in cohorts $B$, cardiovascular disorders and diabetes mellitus being the most prevalent. H\&NC were located mainly in oropharynx (41.9\%) and oral cavity $(32.3 \%)$ followed by nasopharynx (9.7\%), larynx (9.7\%) and hypopharynx (6.5\%), 71\% of patients had surgery before starting RT and 11 patients received concomitant cisplatin-based CT. In patients with $\mathrm{BC}, 70.7 \%$ of tumors were located in the upper outer quadrant and $92 \%$ had stage I or II tumors. Median time from diagnosis to inclusion was 3.5 months. All patients in cohorts A were treated with IMRT and/or VMAT while in cohorts B, $51.2 \%$ were treated by RT-3D. The median number of CareMin650 sessions per week was 3.88 and the percentage of weeks with at least 3 sessions was $87.5 \%, 100 \%, 83.3 \%$ and $100 \%$ in cohorts $A 1, A 2, B 1$ and B2 respectively.

- Safety

In total, 1,312 sessions of CareMin650 were performed during the study, including 530, 156, 455 and 171 in cohorts A1, A2, B1 and B2 respectively. Nine patients reported 14 treatment-emergent adverse events, none of which being related to the device.

- $\mathrm{OM}$ and RD lesions, preventive setting

The PP population comprised 36 patients (17 and 19 in cohorts $A 1$ and $B 1$ respectively). The median number of areas requiring application of pads was 3 in cohort A1 and 2 in cohort B1. All patients developed some degree of $\mathrm{OM}$ and/or RD lesion. Median time from start of CareMin650 to first lesion was 20 days in both cohorts, ranging from 7 to 34 days in cohort A1, from 3 to 49 days in cohort B1 (Supplementary Figs. 2 and 3). Most lesions were grade 1 or 2 (Table 2). Only 1 patient developed G3 RD 
in cohort B1 (left axilla), diagnosed after the end of RT at the follow-up visit, G3 upfront. Four patients had G3 OM in cohort A1, after 7, 14, 19 and 25 days, mean $16.25 \pm 7.63$ days, median: 16.5 days. One lesion, located on hard palate was diagnosed at grade 3 upfront. Other lesions were diagnosed at grade 1 (one case, tongue and cheek) or at grade 2 (two cases, tongue and cheek in one patient, lips in another patient). In the mITT population $(n=45)$, the maximal grade of lesions throughout the study was 0 in one patient (cohort B1), 1 in 12 patients [3 (13.6\%) in A1, 9 (39.2\%) in B1], 2 in 25 patients [13 (59.1\%) in A1, 12 $(52.2 \%)$ in B1] and 3 in 7 patients [6 (27.3\%) in A1 and $1(4.3 \%)$ in B1]. The 2 additional patients with G3 OM had started CareMin650 on day 7 and day 5 of RT respectively.

- $\mathrm{OM}$ and RD lesions, curative setting

At inclusion, the median number of lesions was $2(1-3)$ in cohort A2 and $1(1-4)$ in cohort B2. The median time from start of RT to inclusion was 27 days $(9-40)$ and 25 days (11-41) respectively. In the PP population $(n=22)$, the maximal grade of lesions at inclusion in cohorts A2 and B2 was 1 in $62.5 \%$ and $78.6 \%$ of cases respectively, 2 in $25.0 \%$ and $21.4 \%$ of cases and 3 in $12.5 \%$ and $0 \%$ of cases. At the end of radiotherapy visit, $15 / 21$ patients $(71.4 \%)$ had a maximal grade equal to or lower than that of inclusion (Table 3). At the follow-up visit, lesions had disappeared in 3 patients from cohort B2 (one with G1 and 2 with $\mathrm{G} 2$ lesion at inclusion). In the mITT population $(n=27)$, results were similar with $69 \%$ of patients showing stabilization or improvement at the end of RT and disappearance of all lesions in 4 cases at the follow-up visit (cohort B2).

\section{- Other criteria}

In 57 patients data on pain were available at inclusion and at least once during the study. Mean maximal pain during the study was the highest in cohorts $A 2(42.9 \pm 26.3)$ and $A 1(35.8 \pm 28.1)$ while it remained low in cohorts B1 (11.6 \pm 15.5 and $11.1 \pm 17.8$ respectively). Data on pain are shown in Supplementary Table 1.

Data on patient's satisfaction were available for 64 patients. A majority of patients declared that the application of the device was not burdensome (81.3\%), provoked no discomfort (76.6\%), and that the duration of sessions was acceptable (68.8\%). Overall, $87.5 \%$ reported no pain at all during applications, while 5 (7.8\%) reported slight but tolerable pain and only 3 (15.8\%), all in cohort A1, found the application quite painful. The patient preferred maintaining the device in contact with skin or mucosa himself during the session in $89.1 \%$ of cases. Overall, most patients were very satisfied $(60.3 \%)$ or satisfied $(33.3 \%)$ with the device. The application of CareMin 650 was performed by physicians, nurses, residents, radiologic technologists or clinical research assistants, depending on sites decision and organization. The installation of the device was considered easy in all cases (very easy: $79.4 \%$; rather easy: $20.6 \%$ ). The device was considered very handy, rather handy and rather unhandy in $69.1 \%, 22.1 \%$ and $8.8 \%$ of cases respectively. Duration of sessions was assessed as rather short, acceptable and rather long in $4.4 \%, 73.5 \%$ and $22.1 \%$ of cases respectively. Overall, users found the device rather satisfactory $(71.6 \%)$ or very satisfactory $(23.9 \%)$ and $87.5 \%$ declared that they would like to use it in routine practice. 


\section{Discussion}

Although PBM demonstrated efficacy and safety in a number of randomized clinical trials and metaanalyses ${ }^{23-27}$, it is rarely used in routine practice. Indeed, treatment is time consuming, equipment is cumbersome and unwieldy; lasers are set with various parameters (wavelength, irradiance, pulse structure, coherence, polarization, energy, fluence) resulting in lack of standardisation. Finally, the procedure is not fully reproducible and operator dependent as the distance from the skin or mucosa is difficult to assess accurately. Thus, the amount of energy delivered cannot be exactly known. CareMin650 is a small and handy device allowing reproducible and accurately controlled delivery of light thanks to direct application of lightning tissue on skin and mucosa. This study aimed at evaluating its feasibility and safety in as many situations as possible, leading to inclusion of 4 subgroups of patients, who underwent applications of pads on mucosa and/or skin, on intact or damaged tissues. The study was performed at highly experienced radiotherapy sites. Characteristics of radiotherapy reflect usual practice with IMRT/VMAT being used in all H\&NC patients while one half of patients with BC received RT-3D. Duration, total dose and dose per fraction are consistent with current recommendations. The percentage of patients receiving concomitant chemotherapy was quite low (33\%) but not unusual.

The study protocol recommended at least 3 sessions per week, ideally 5 . Compliance to treatment was good with a median number of 3.88 sessions per week, which suggests that CareMin650 therapy is feasible even in sites with high patient flow. Indeed, the device is easy to use as the operator only needs to select a dose and the lightbox automatically calculates the duration of application required to deliver this dose. Therefore, application can be performed by any healthcare professional who has been properly trained. In this study, physicians, residents, nurses, radiologic technologists or CRAs were in charge of device utilization.

PBM is known to have good local tolerance ${ }^{6,23}$. However, a possible concern with CareMin650 was that direct contact of a pad on skin or mucosa could provoke pain or irritation, especially in case of pre-existing lesion. Our results show that local tolerance was very good as no device-related adverse event relating to local pain, irritation or unpleasant feelings has been reported during 1,312 sessions. In particular, all patients from cohort A2 reported that application was not painful, and overall, only 3 patients $(4.7 \%)$ declared that the application was rather painful and provoked discomfort. Concerns on risks of PBMrelated proliferation of tumor cells have been raised and extensively debated due to conflicting in vitro data. However, the use of PBM for more than 30 years, the increasing number of published data in OM prevention in H\&NC and SCT patients suggest that PBM does not influence tumor or treatment outcomes and overall survival ${ }^{28}$. Data in H\&NC patients treated with LLLT during RT without prior surgery and longterm follow-up are very reassuring ${ }^{7}$. Specific evaluation of CareMin650 in an in vitro study showed that irradiated cancer cells do not proliferate when illuminated ${ }^{29}$.

The study was not designed to demonstrate efficacy. However, preliminary findings can be observed. Only one case of grade 3 RD occurred in the preventive cohorts, and it was diagnosed after the end of RT, therefore did not occur during CareMin650 treatment. 
In H\&NC patients, grade $3 \mathrm{OM}$ occurred in 4 cases (23.5\%), which is lower than reported in the literature, as incidence is usually around $50 \%$ and in any case, always exceeds $30 \%$ in the absence of efficacious preventive treatement ${ }^{1,3}$. Importantly, these 4 cases occurred at the same investigational site, among 5 patients included. This discrepancy between sites could be explained by several hypotheses. First, a high variability has been shown in the grading of OM lesions using CTCAEv3 criteria, with discordance rates of $34 \%$ between local investigators and central review ${ }^{30}$. In our study, lesions were graded locally, and no training had been implemented at the beginning of the study to standardize grading. Thus, a very likely explanation lies in the variable analysis of lesions across sites, although grading was to be performed by a physician. The choice of CTCAEv3 for grading had been made because it was considered more accurate than WHO grading scale or CTCAEv5. However, it is also more difficult to use and the distinction between grade 2 and 3 appears very difficult and subject to investigator's interpretation. Moreover, the choice of grading scale can influence the results. In our study, among patients with food intake limitations, only 3 had G3 OM; therefore, using WHO grading scale, the number of patients with G3 OM lesions would probably have been 3 . Second, it has been observed that some lesions were reported late, although symptoms suggesting $\mathrm{OM}$ had been described days or weeks earlier, leading to delay in dose increase. This highlights the importance of early detection of lesions with dose increase to $6 \mathrm{~J} / \mathrm{cm}^{2}$ as soon as a $\mathrm{G} 1$ lesion appears. Finally, differences in patients' population might partly explain a higher incidence of severe lesions, for example different exposures to tobacco and alcohol in one site (North of France) compared to others. Unfortunately, alcohol consumption and smoking status were not recorded in this study. In the ITT population, 2 additional patients developed G3 OM lesions. Both had started CareMin650 several days after the start of RT, suggesting that starting PBM on day 1 of RT is probably key for prevention of OM. No conclusion can be drawn on the effects of CareMin650 in curative settings at this point, due to the small sample size. However, it seems that lesions were stabilized or improved in most cases, although treatment started at grade 2 or 3 in $27 \%$ of cases. Finally, safety and efficacy are not the only criteria for a therapy to be implemented in clinical practice. It has to be acceptable for patients and healthcare professionals. In this study, patients' and users' questionnaires showed the high rate of satisfaction towards the device.

This study has limitations. It was not a randomized controlled trial, so that no conclusion can be drawn on efficacy. As already mentioned, no standardization training for grading had been performed which raises questions on consistency across investigators. Some data are lacking to better interpret the results, such as smoking habits or alcohol consumption. Finally, the size of each cohort was low, especially in curative settings. Recruitment turned out to be easier in cohorts A1 and B1 that were almost completed when the covid-19 pandemic started. At this time, inclusions were put on hold and ongoing treatments were interrupted, leading to a high number of early study discontinuations. Inclusions resumed after 3 months, in some but not all sites, at a very low rate and it was eventually decided to stop the study as the overall target had been reached, despite the imbalance between cohorts.

\section{Conclusion}

$\mathrm{OM}$ and RD are frequent and disabling adverse effects of RT. Every effort should be made to reduce their incidence and severity in order to improve patients' quality of life and optimize supportive care. PBM is not 
routinely used despite proven efficacy and clear recommendations, because of the lack of easy-to-use and reliable equipment. The new CareMin650 device has shown very good safety and tolerance as well as promising efficacy results, that will require confirmation in a larger prospective trial to allow wider utilization in daily practice.

\section{Declarations}

Funding : No funding

Conflicts of interest/Competing interests: No Conflict of interest.

Availability of data and material: Yes.

Code availability: Yes.

Authors' contributions : All authors contribute equally to study desigh, protocol élaboration, patients inclusion, data analyse, and manuscript writing and review.

Ethics approval : the study was approved by the " Comite de Protection des Personnes (CPP) CPP Sud-Est VI » and by the ANSM (Agence Nationale du Médicament et des Produits de Santé).

Consent to participate : All patients approved to participate in the study, and to participate in paper's preparation, writing, and internal review.

Consent for publication: All authors approved paper submission to the « Journal of Supportive Care in Cancer », and accepted the publication of this paper in this journal.

\section{References}

1. Lalla RV, Bowen J, Barasch A et al (2014) MASCC/ISOO clinical practice guidelines for the management of mucositis secondary to cancer therapy. Cancer 120(10):1453-1461

2. Scully C, Sonis S, Diz PD (2006) Oral mucositis. Oral Dis 12(3):229-241

3. Trotti A, Bellm LA, Epstein JB et al (2003) Mucositis incidence, severity and associated outcomes in patients with head and neck cancer receiving radiotherapy with or without chemotherapy: a systematic literature review. Radiother Oncol 66(3):253-262

4. Elting LS, Cooksley CD, Chambers MS, Garden AS (2007) Risk, outcomes, and costs of radiationinduced oral mucositis among patients with head-and-neck malignancies. Int $\mathrm{J}$ Radiat Oncol Biol Phys 68(4):1110-1120

5. Murphy BA, Beaumont JL, Isitt J et al (2009) Mucositis-related morbidity and resource utilization in head and neck cancer patients receiving radiation therapy with or without chemotherapy. J Pain Symptom Manage 38(4):522-532 
6. Antunes HS, Herchenhorn D, Small IA et al (2013) Phase III trial of low-level laser therapy to prevent oral mucositis in head and neck cancer patients treated with concurrent chemoradiation. Radiother Oncol 109(2):297-302

7. Antunes HS, Herchenhorn D, Small IA et al (2017) Long-term survival of a randomized phase III trial of head and neck cancer patients receiving concurrent chemoradiation therapy with or without low-level laser therapy (LLLT) to prevent oral mucositis. Oral Oncol 71:11-15

8. Bensadoun RJ, Franquin JC, Ciais G et al (1999) Low-energy He/Ne laser in the prevention of radiation-induced mucositis. A multicenter phase III randomized study in patients with head and neck cancer. Support Care Cancer 7(4):244-252

9. Gautam AP, Fernandes DJ, Vidyasagar MS, Maiya AG, Vadhiraja BM (2012) Low level laser therapy for concurrent chemoradiotherapy induced oral mucositis in head and neck cancer patients - a triple blinded randomized controlled trial. Radiother Oncol 104(3):349-354

10. Oton-Leite AF, Elias LS, Morais MO et al (2013) Effect of low level laser therapy in the reduction of oral complications in patients with cancer of the head and neck submitted to radiotherapy. Spec Care Dentist 33(6):294-300

11. Gautam AP, Fernandes DJ, Vidyasagar MS, Maiya AG, Guddattu V (2015) Low level laser therapy against radiation induced oral mucositis in elderly head and neck cancer patients-a randomized placebo controlled trial. J Photochem Photobiol B 144:51-56

12. Elad S, Cheng KKF, Lalla RV et al. MASCC/ISOO clinical practice guidelines for the management of mucositis secondary to cancer therapy. Cancer 2020

13. Zadik Y, Arany PR, Fregnani ER et al (2019) Systematic review of photobiomodulation for the management of oral mucositis in cancer patients and clinical practice guidelines. Support Care Cancer 27(10):3969-3983

14. Seite S, Bensadoun RJ, Mazer JM (2017) Prevention and treatment of acute and chronic radiodermatitis. Breast Cancer 9:551-557

15. Wong RK, Bensadoun RJ, Boers-Doets CB et al (2013) Clinical practice guidelines for the prevention and treatment of acute and late radiation reactions from the MASCC Skin Toxicity Study Group. Support Care Cancer 21(10):2933-2948

16. Kole AJ, Kole L, Moran MS (2017) Acute radiation dermatitis in breast cancer patients: challenges and solutions. Breast Cancer 9:313-323

17. Robijns J, Censabella $S$, Claes $S$ et al. Prevention of acute radiodermatitis by photobiomodulation: A randomized, placebo-controlled trial in breast cancer patients (TRANSDERMIS trial). Lasers Surg Med 2018

18. Hamblin MA, de Sousa T (2016) M. Handbook of Low-Laser Therapy. Pan Stanford Publishing

19. Huang YY, Sharma SK, Carroll J, Hamblin MR (2011) Biphasic dose response in low level light therapy - an update. Dose Response 9(4):602-618

20. Courtois E, Bouleftour W, Guy JB et al (2021) Mechanisms of PhotoBioModulation (PBM) focused on oral mucositis prevention and treatment: a scoping review. BMC Oral Health 21(1):220 
21. Fekrazad R, Chiniforush $\mathrm{N}$ (2014) Oral mucositis prevention and management by therapeutic laser in head and neck cancers. J Lasers Med Sci 5(1):1-7

22. Begaud B (1998) Dictionnaire de Pharmaco-épidémiologie. 3e édition. Bordeaux

23. Bjordal JM, Bensadoun RJ, Tuner J, Frigo L, Gjerde K, Lopes-Martins RA (2011) A systematic review with meta-analysis of the effect of low-level laser therapy (LLLT) in cancer therapy-induced oral mucositis. Support Care Cancer 19(8):1069-1077

24. Oberoi S, Zamperlini-Netto G, Beyene J, Treister NS, Sung L (2014) Effect of prophylactic low level laser therapy on oral mucositis: a systematic review and meta-analysis. PLoS ONE 9(9):e107418

25. Clarkson JE, Worthington HV, Furness S, McCabe M, Khalid T, Meyer S. Interventions for treating oral mucositis for patients with cancer receiving treatment. Cochrane Database Syst Rev 2010; (8): CD001973

26. Migliorati C, Hewson I, Lalla RV et al (2013) Systematic review of laser and other light therapy for the management of oral mucositis in cancer patients. Support Care Cancer 21(1):333-341

27. Bensadoun RJ, Nair RG (2012) Low-level laser therapy in the prevention and treatment of cancer therapy-induced mucositis: 2012 state of the art based on literature review and meta-analysis. Curr Opin Oncol 24(4):363-370

28. Bensadoun RJ, Epstein JB, Nair RG et al. Safety and efficacy of photobiomodulation therapy in oncology: A systematic review. Cancer Med 2020

29. Courtois E, Guy JB, Axisa F et al. Photobiomodulation by a new optical fiber device: analysis of the in vitro impact on proliferation/migration of keratinocytes and squamous cell carcinomas cells stressed by X-rays. Lasers Med Sci 2020

30. Ueno T, Zenda S, Konishi T et al (2019) The post hoc analysis comparing the severity grades of chemoradiotherapy-induced oral mucositis scored between the central and local assessors in a multicenter, randomized controlled trial of rebamipide for head and neck cancer. Int J Clin Oncol 24(3):241-247

\section{Tables}

Table 1: Patients' characteristics at baseline 


\begin{tabular}{|c|c|c|c|c|c|}
\hline $\begin{array}{l}\text { Parameter } \\
\text { (Unit) }\end{array}$ & & $A 1, n=22$ & $A 2, n=9$ & $B 1, n=23$ & $B 2, n=18$ \\
\hline Statistics / Category & & & & & \\
\hline Age (years), median (ran & & 63.4 & 58.6 & 59.2 & 58.5 \\
\hline & & $\begin{array}{l}(37.9 ; \\
83.8)\end{array}$ & $\begin{array}{l}(36.9 ; \\
81.7)\end{array}$ & $81.3)$ & $86.3)^{(37.8 ;}$ \\
\hline Females, n (\%) & & $5(22.7 \%)$ & $1(11.1 \%)$ & $23(100.0 \%)$ & $18(100.0 \%)$ \\
\hline Males, n (\%) & & $17(77.3 \%)$ & $8(88.9 \%)$ & $0(0.0 \%)$ & $0(0.0 \%)$ \\
\hline BMI $\left(\mathrm{kg} / \mathrm{m}^{2}\right)$, median & nge) & 25.3 & 22.3 & 25.0 & 24.3 \\
\hline & & $\begin{array}{l}(17.6 \text {; } \\
32.0)\end{array}$ & ${ }^{(17.2 .2 ;}$ & $43.1)^{(19.6 ;}$ & $\begin{array}{l}(17.5 ; \\
33.9)\end{array}$ \\
\hline Comorbidities, n (\%) & & $19(86.4 \%)$ & $6(66.7 \%)$ & $14(60.9 \%)$ & $8(44.4 \%)$ \\
\hline ECOG PS & 0 & $12(54.5 \%)$ & $6(66.7 \%)$ & $20(87.0 \%)$ & $17(94.4 \%)$ \\
\hline & 1 & $9(40.9 \%)$ & $2(22.2 \%)$ & $3(13.0 \%)$ & $1(5.6 \%)$ \\
\hline & 2 & $1(4.5 \%)$ & $1(11.1 \%)$ & $0(0.0 \%)$ & $0(0.0 \%)$ \\
\hline $\begin{array}{l}\text { Time from diagnosis of } \\
\text { cancer }\end{array}$ & $\begin{array}{l}\text { Mean }(+/- \\
S D)\end{array}$ & 3.22 & & & \\
\hline (months) & & $(+/-3.00)$ & $(+/-0.35)$ & $(+/-55.32)$ & $(+/-2.34)$ \\
\hline & Min ; Max & $0.95 ; 18.20$ & $2.30 ; 3.51$ & $\begin{array}{l}1.31 ; \\
270.92\end{array}$ & $2.07 ; 10.89$ \\
\hline & Median & 2.13 & 2.87 & 6.10 & 3.90 \\
\hline Tumor stage at & I (or Tis) & $4(18.2 \%)$ & $5(55.6 \%)$ & $10(43.5 \%)$ & $7(50.0 \%)$ \\
\hline & II & $8(36.4 \%)$ & $2(22.2 \%)$ & $11(47.8 \%)$ & $6(42.9 \%)$ \\
\hline & III & $7(31.8 \%)$ & $0(0.0 \%)$ & $2(8.7 \%)$ & $1(7.1 \%)$ \\
\hline & IVa & $3(13.6 \%)$ & $1(11.1 \%)$ & 0 & 0 \\
\hline & $I V C$ & $0(0.0 \%)$ & $1(11.1 \%)$ & 0 & 0 \\
\hline Surgery & & $16(72.7 \%)$ & $6(66.7 \%)$ & $23(100.0 \%)$ & $17(94.4 \%)$ \\
\hline Chemotherapy & & $8(36.4 \%)$ & $3(33.3 \%)$ & $3(13.0 \%)$ & $0(0.0 \%)$ \\
\hline Total duration of RT, wee & s, median & $\begin{array}{l}6.86(4.86 \\
8.71)\end{array}$ & $\begin{array}{l}6.71(5.00 ; \\
7.29)\end{array}$ & $\begin{array}{l}6.29(2.86 ; \\
7.43)\end{array}$ & $\begin{array}{l}5.86(4.71 \\
7.00)\end{array}$ \\
\hline Total dose of RT (Gy), m & lian (range) & $66(50 ; 70)$ & $66(56 ; 70)$ & $66(40 ; 66)$ & $63(50 ; 66)$ \\
\hline Dose per fraction (Gy), m & dian (range) & 2.00 & 2.00 & 2.00 & 2.00 \\
\hline
\end{tabular}




\begin{tabular}{|c|c|c|c|c|}
\hline & $2.50)^{(1.59 ;}$ & $2.09)^{(1.71 ; ~}$ & $2.80)$ & $2.52)^{(2.00}$ \\
\hline $\begin{array}{l}\text { Total number of Caremin sessions, } \\
\text { median (range) }\end{array}$ & $29(7 ; 38)$ & $14(4 ; 40)$ & $21(4 ; 33)$ & $8(1 ; 24)$ \\
\hline $\begin{array}{l}\text { Sessions of CareMin per week, median } \\
\text { (range) }\end{array}$ & $\begin{array}{l}4.06 \\
(1.75 ; \\
5.00)\end{array}$ & $\begin{array}{l}4.33 \\
\quad(3.00 ; \\
5.00)\end{array}$ & $\begin{array}{l}3.29 \\
(2.00 ; \\
5.00)\end{array}$ & $\begin{array}{l}4.00 \\
(1.00 ; \\
5.00)\end{array}$ \\
\hline
\end{tabular}

Table 2: Type and grade of lesions, preventive setting, per protocol population

\begin{tabular}{|lll|}
\hline Type of lesions & A1, $\mathbf{n}=17$ & B1, $\mathbf{n = 1 9}$ \\
\hline Nb patients with OM & $16(94.1 \%)$ & $0(0 \%)$ \\
\hline Nb patients with RD & $11(64.7 \%)$ & $19(100 \%)$ \\
\hline OM only & $6(35.3 \%)$ & $0(0 \%)$ \\
\hline RD only & $1(5.9 \%)$ & $19(100 \%)$ \\
\hline OM + RD & $10(58.8 \%)$ & $0(0 \%)$ \\
\hline Maximal grade, any lesion & & \\
1 & $3(17.6 \%)$ & $8(42.1 \%)$ \\
2 & $10(58.8 \%)$ & $10(52.6 \%)$ \\
3 & $4(23.5 \%)$ & $1(5.3 \%)$ \\
\hline
\end{tabular}

Table 3: Maximal grades reported during the study, at the end of radiotherapy visit and at follow-up visit compared to inclusion, curative setting, per protocol population 


\begin{tabular}{|c|c|c|c|c|c|c|c|c|}
\hline & \multicolumn{4}{|c|}{ Cohort A2, n=8 } & \multicolumn{4}{|c|}{ Cohort B2, n=14 } \\
\hline & \multicolumn{2}{|c|}{ During treatment } & \multirow{2}{*}{$\begin{array}{l}\text { End of } \\
\text { RT } \\
\text { Highest } \\
\text { max } \\
\text { grade }\end{array}$} & \multirow{2}{*}{$\begin{array}{l}\text { FU visit } \\
\text { Highest } \\
\text { max } \\
\text { grade }\end{array}$} & \multicolumn{2}{|c|}{ During treatment } & \multirow{2}{*}{$\begin{array}{l}\text { End of } \\
\text { RT } \\
\text { Highest } \\
\text { max } \\
\text { grade }\end{array}$} & \multirow{2}{*}{$\begin{array}{l}\text { FU visit } \\
\text { Highes } \\
\text { max } \\
\text { grade }\end{array}$} \\
\hline & $\begin{array}{l}\text { Lowest } \\
\text { max } \\
\text { grade }\end{array}$ & $\begin{array}{l}\text { Highest } \\
\text { max } \\
\text { grade }\end{array}$ & & & $\begin{array}{l}\text { Lowest } \\
\text { max } \\
\text { grade }\end{array}$ & $\begin{array}{l}\text { Highest } \\
\text { max } \\
\text { grade }\end{array}$ & & \\
\hline Stable & 6 & 2 & 0 & 4 & 10 & 11 & 11 & 2 \\
\hline Improved -1 & 1 & 0 & 2 & 1 & 3 & 0 & 2 & 3 \\
\hline Improved -2 & 1 & 0 & 0 & 0 & 1 & 0 & 0 & 1 \\
\hline Worsened +1 & 0 & 6 & 6 & 2 & 0 & 3 & 0 & 0 \\
\hline Worsened +2 & 0 & 0 & 0 & 0 & 0 & 0 & 0 & 0 \\
\hline $\begin{array}{l}\text { Disappearance } \\
\text { of lesions }\end{array}$ & 0 & 0 & 0 & 0 & 0 & 0 & 0 & 3 \\
\hline Missing & 0 & 0 & 0 & 1 & 0 & 0 & 1 & 8 \\
\hline
\end{tabular}

\section{Figures}

\section{A: Light box and oral pads}

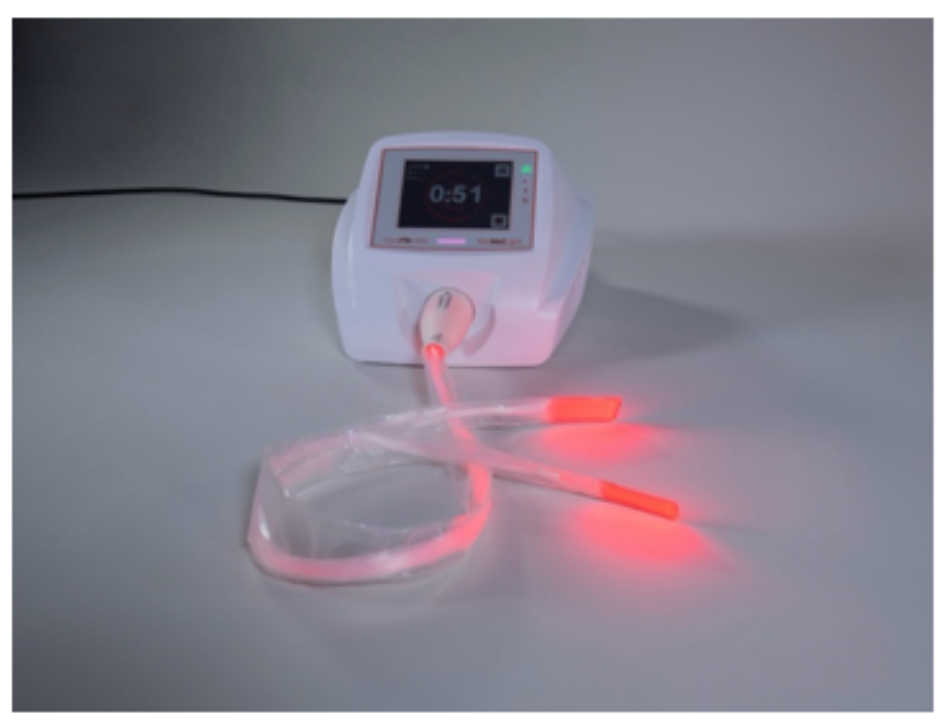

B: light box and derma pad

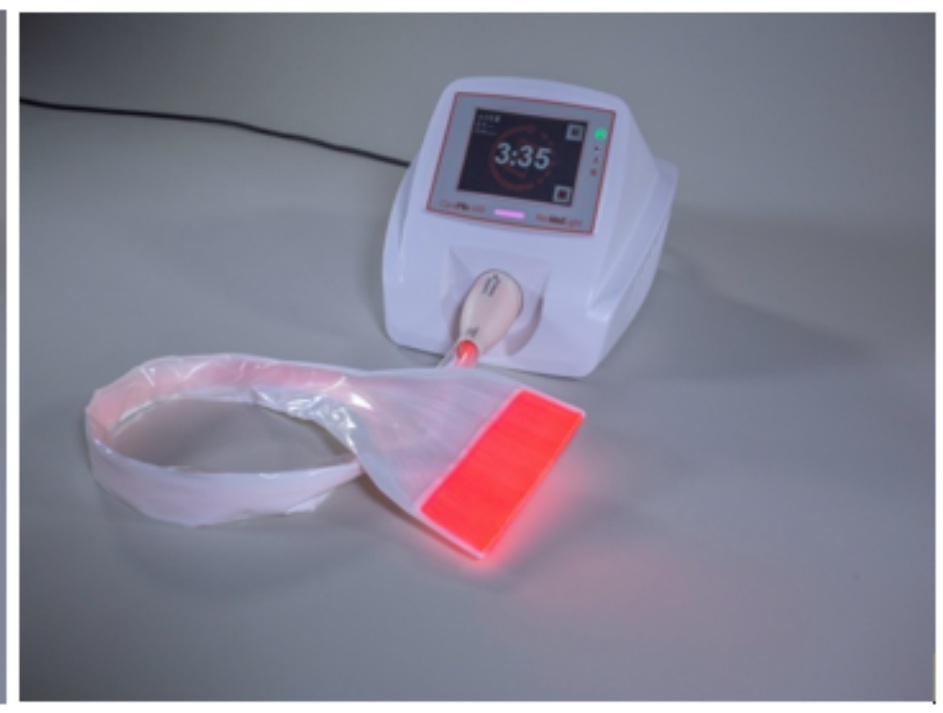

Figure 1

CareMin650 


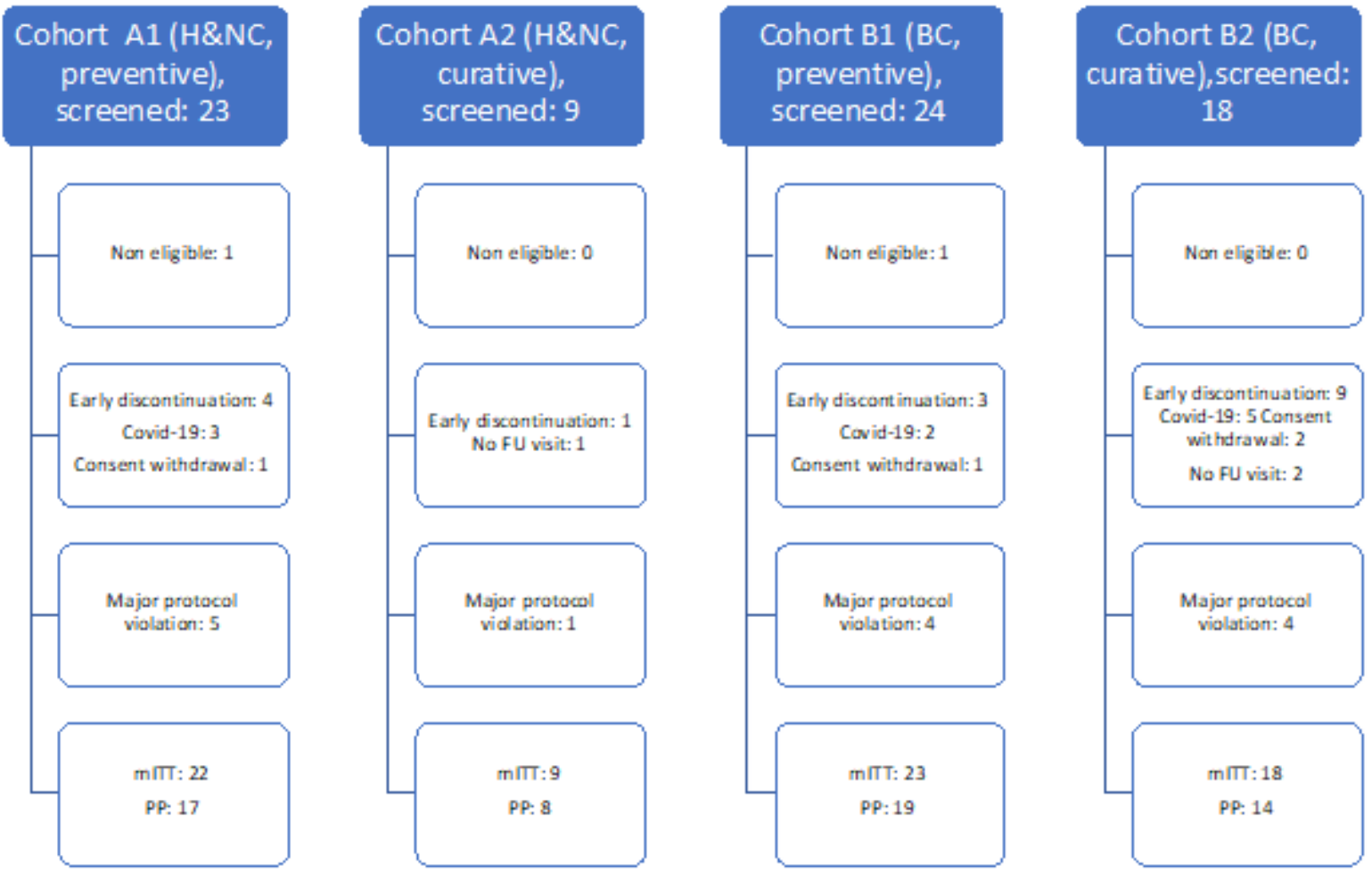

Figure 2

Disposition of patients

\section{Supplementary Files}

This is a list of supplementary files associated with this preprint. Click to download.

- SupplementaryTablesandFigures.docx 